\title{
Lenguaje heráldico, diseño e institución pública
}

Joan Sanz Sánchez Universidad de Granada, Lic.

RECIBIDO: 28.02.2018 / ACEPTADO: 10.04.2018

\section{Resumen}

El lenguaje heráldico es un recurso estratégico en el diseño de identidades visuales institucionales. Los objetivos de este trabajo son: 1) describir las relaciones entre el lenguaje heráldico y el actual concepto de diseño de identidad visual corporativa; 2) identificar la problemática que encuentran diseño e institución para conseguir una comunicación de identidad efectiva y de calidad.

Palabras clave: diseño, identidad visual corporativa, heráldica, institución pública.

\section{The emotion of a handmade light by arturo alvarez}

\section{Abstract}

The heraldic language is a strategic resource for designing the visual identity of institutions. The goals of this paper are: 1) the description of the relationships between the heraldic language and the current concept of visual corporate design; 2) the identification of possible problems that the design and the institution could find to get an excellent and effective communication of the institution identity.

Keywords: design, corporate visual identity, heraldry, public institution.

\footnotetext{
Joan Sanz Sánchez, es licenciado en Bellas Artes por la Universidad de Granada, con estudios de doctorado en el máster oficial «Tipografía. Disciplina y usos» de la Universidad de Barcelona, y con estudios de posgrado en "Gestión de proyectos multimedia» en el Centro Universitario de Diseño y Arte de Barcelona Eina. Ilustrador y diseñador gráfico es colaborador habitual de diversas editoriales y publicaciones de ámbito nacional y desarrolla paralelamente su carrera docente como profesor en materias de diseño en la facultad de Bellas Artes de Granada y en Enseñanzas Artísticas Superiores. Realiza su tesis doctoral sobre «La comunicación gráfica en la imagen institucional universitaria» abordada desde la práctica del rediseño de la marca institucional y el desarrollo de su implementación en la Universidad de Granada. Correo electrónico: jsanz@ugr.es
} 


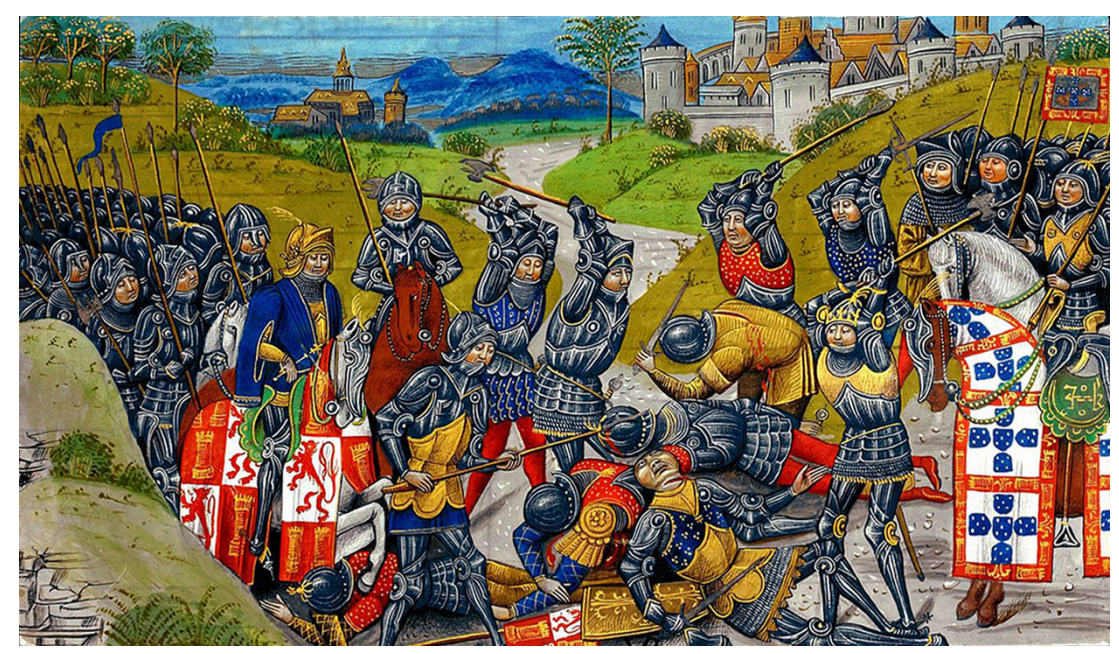

Fig.1. Batalla de Aljubarrota, 1385.

\section{Heráldica y diseño de identidad}

El concepto de identidad visual corporativa tiene un origen de reconocimiento consensuado en la heráldica nobiliaria y en las enseñas gremiales y personales. Esto es así porque la función heráldica es la misma que le ocupa a la actual concepción de identidad visual corporativa, la función de ambos recursos de representación trata la identificación, la distinción, la diferenciación, la pertenencia y el afecto.

La heráldica concentra la idea de su origen en una suerte de contexto bélico y militar. En las batallas o torneos de la Edad Media, cuando los actores en disputa se ocultaban tras similares armaduras, la distinción a través del color y las formas resultaba un recurso de gran valor identificativo y diferenciador. Siendo diverso y amplio el campo de aplicación heráldica, es el escudo, por su tamaño y disposición, el lugar donde se concentran estas visualizaciones y el estudio de su representación.

Bien es cierto que la identificación no sería un terreno exclusivo de la contienda armada caballeresca, sino que ya anteriormente la necesidad de marcar podría considerarse generalizada. Joan Costa nos recuerda ánimos de identificación comercial y profesional desde la Antigüedad, los signos e imágenes en el cuño de las monedas, las marcas de propiedad de los alfareros en las ánforas, marcas constructivas y profesionales como las de los de canteros, marcas comerciales, marcas personales... han existido siempre. Coincide además, para reforzar esta diversidad de signos, que con el desarrollo de la Edad Media y el Renacimiento, se produce la consolidación social de comerciantes, artesanos y profesionales liberales que refuerzan su identificación también mediante señales significativas. «En una primera etapa la enseña comercial sigue las pautas griegas y romanas colgando de un clavo, en lo alto de la puerta del establecimiento, los productos en venta; más tarde se colocarán al extremo de un palo perpendicularmente a la fachada de la tienda para hacerlos más visibles a distancia (en un recurso probablemente imitado de las banderas), para acabar sustituyendo los productos reales por su referencia icónica» ${ }^{1}$. Aquí Satué nos habla del valor connotativo de este «nuevo poder

1 SATUÉ, E. El diseño gráfico. Desde los orígenes hasta nuestros días, Alianza, Madrid 2006, p. 24. 
simbólico", de cómo los signos gráficos sustituyen al objeto, y la idea de aquel, sus asociaciones derivadas, es aludida por la representación.

El escudo será el ensayo para la aplicación de signos distintivos en un marco soporte.

La distinción a través del color primero, las divisiones, las direcciones y composiciones de las particiones cromáticas en la superficie del escudo, las piezas o formas, y la aplicación posterior de muebles y figuras, generarían un amplio programa de recursos visuales diferenciales e inequívocos, muy recurrentes para dar servicio a personalidades y entidades de índole política, institucional o comercial. «Los colores y más códigos, que fueron incorporados por la heráldica, serían la prefiguración de uno de los pilares de la retórica visual de las marcas comerciales en la revolución industrial ocho siglos después»².

Así debemos reconocerle a la heráldica que supone una de las más importantes influencias en la transformación de las formas de representación identitaria, que del ámbito militar trascenderían «al ámbito feudal, civil y finalmente, productivo de los artesanos, mercaderes y de los oficios ". Debemos reconocerle además una aportación trascendental a la actual concepción del diseño, la heráldica, a través de sus códigos y leyes, establece un concepto normativo, una regla de aplicación precisa justificada en su propia funcionalidad, hablamos de los programas de diseño de identidad, "Anotemos aquí una observación: el «sistema» de la heráldica no está lejos de aquel que hemos encontrado en las ánforas de la Antigüedad. La marca identitaria no era solamente el sello incidido sobre el barro, como en la heráldica no los son sólo las figuras. Toda una estructura significante articulaba la identificación de las ánforas, como también la de los escudos. Aquí empezamos a vislumbrar la arquitectura de la identidad visual y — tal vez- el embrión de los sistemas de identidad gráfica corporativa»"${ }^{4}$.

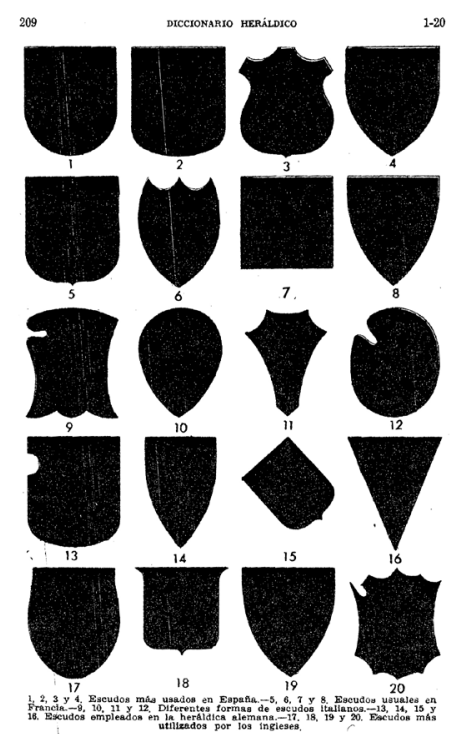

Fig.2. Formas de escudos según procedencia.

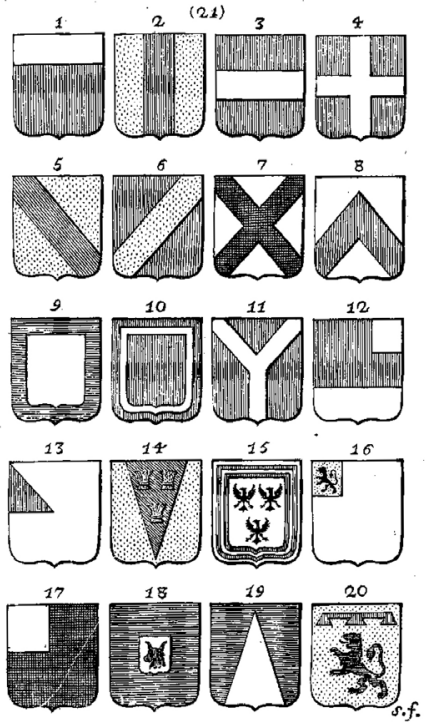

Fig.3. Grabados calcográficos de heráldica.

\footnotetext{
2 COSTA, J. La imagen de marca. Un fenómeno social, Paidós, Barcelona 2009, p. 53.

3 Ibidem, p. 54.

4 Ibidem, p. 65.
} 


\section{La estrategia heráldica en el diseño de identidad}

Si los comerciantes, artesanos y sus gremios tomaron algo de la heráldica en su modo identificador, su aportación es también significativa. Al prestigio de las figuras del recuerdo, al reconocimiento del parentesco genealógico nobiliario, la relación de la imagen de identidad con el corporativismo de los gremios profesionales añade a la identificación baluartes de calidad y de garantía.

Desgranemos pues las funciones que le son propias a la heráldica y las adquiridas a través del lenguaje corporativista. Las relacionamos con las actuales funciones de la identidad visual corporativa y exponemos paralelamente el conjunto de características que esta requiere ${ }^{5}$ :

\begin{tabular}{|c|c|c|c|}
\hline \multicolumn{2}{|c|}{ Siglos XII - XVII } & \multirow{2}{*}{\multicolumn{2}{|c|}{$\begin{array}{c}\text { Siglos XVIII - Actualidad } \\
\text { Identidad Visual Corporativa }\end{array}$}} \\
\hline Identificación Heráldica & Identificación Corporativa & & \\
\hline Funciones & Funciones & Funciones & Características \\
\hline Identificación & Identificación & Identificación & \multirow{10}{*}{$\begin{array}{c}\text { Pertinencia tipológica } \\
\text { Individualidad } \\
\text { Pertinencia estilística } \\
\text { Capacidad emblemática } \\
\text { Calidad gráfica } \\
\text { Vigencia } \\
\text { Versatilidad } \\
\text { Rendimiento técnico }\end{array}$} \\
\hline Diferenciación & Diferenciación & Diferenciación & \\
\hline Reconocimiento & Reconocimiento & Reconocimiento & \\
\hline Parentesco & & Parentesco & \\
\hline Propiedad & Propiedad & Propiedad & \\
\hline \multirow[t]{4}{*}{ Pertenencia } & & Pertenencia & \\
\hline & Calidad & Calidad & \\
\hline & Garantía & Garantía & \\
\hline & Autenticidad & Autenticidad & \\
\hline Oficialidad & Oficialidad & Oficialidad & \\
\hline
\end{tabular}

Debemos observar la linealidad de los conceptos que se repiten precisamente como una constante en el recurso de identificación desde la Edad Media hasta la actualidad. Son las aportaciones consolidadas en estas mecánicas de comunicación. La identidad visual corporativa, coincidente con estas funciones a resolver, explota los recursos de estas tradiciones comunicativas con una conciencia disciplinar que opera con problemas ahora mucho más amplios y complejos. El contexto socio-económico de las sociedades contemporáneas más avanzadas económicamente ha requerido un desarrollo de la identificación que la eleva a una categoría disciplinar altamente tecnificada, metodológica y de gran transversalidad socio-cultural, económico-productiva y artístico-creativa.

El diseño de identidad visual, convertido ahora en disciplina profesional integrada en el sistema productivo, es más consciente de sus funciones, y lo que es más importante, se orienta al receptor de su mensaje, dispone de datos y recursos con los que conocer sus públicos objetivos, detectar sus necesidades e incluso inducirlas. El suyo es un mensaje diseñado con especificidad. La intencionalidad, o el objetivo de la comunicación, discurre atendiendo al perfil del destinatario, de su colectivo. Así, a través de signos gráficos, temperaturas

5 CHAVES, N. La marca país [Conferencia del Seminario de Capacitación sobre el desarrollo de "La marca país»], Jefatura de Gabinete de la Provincia de Buenos Aires (28.08.2012). 
cromáticas e iconografías de un repertorio compartido, el diseño fomenta la creación de un significado de marca y favorece una relación emocional entre la marca y su público. Estas capacidades le permiten al diseño trascender la comunicación hasta la promoción de conductas, gustos estéticos, hábitos de consumo, actitudes sociales o climas de opinión.

\section{Categorización y características de la estrategia}

Hoy la identificación visual corporativa conserva y explota la heráldica y sus recursos. En diferentes maneras y medidas, con mayor o menor acierto, y con más o menos pertinencia, pero en cualquier caso con una lógica de apropiación que resulta altamente recurrente. Encontramos una justa tradición identificativa en la imagen de naciones, gobiernos y estamentos institucionales donde la expresión heráldica se pretende más normativa en el empleo de sus formas y símbolos. Pero la encontramos también en el vasto paisaje de marcas comerciales que adoptan con ella sus valores de prestigio y distinción en su sentido más cualitativo.

Empezaremos describiendo sujetos de aplicación habituales de la identidad visual corporativa que explotan la estrategia heráldica. Establecemos dos grupos diferenciados bajo el eje «público-privado», abordando lo público bajo la generalidad de entidades institucionales y lo privado como conjunto coincidente de lo comercial. Basamos esta diferenciación en el aspecto de la funcionalidad y objetivos que les son propios.
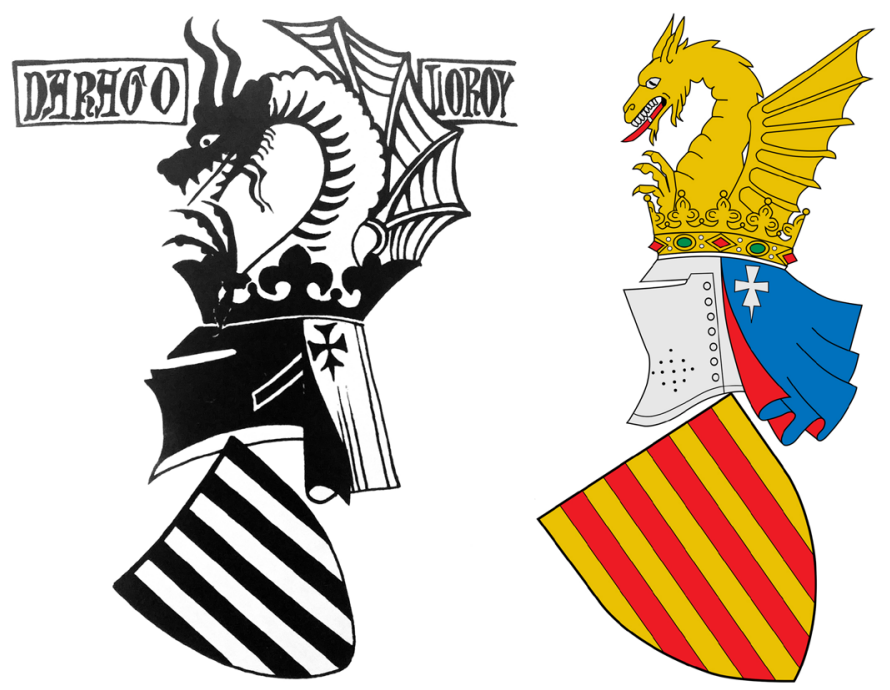

Fig.4. Representación del siglo XVI, Museo Arqueológico Provincial de Valencia y representación heráldica contemporánea del escudo de la Comunidad Valenciana.
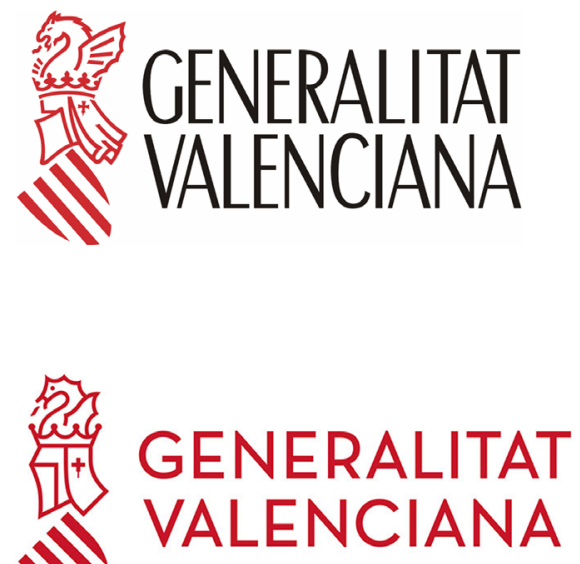

Fig.5. Identidad visual de la Generalitat Valenciana diseñada por La Nave en 1984 y su rediseño de nuevo por Nacho Lavernia y Daniel Nebot en 2018.

La imagen de marca institucional aborda la marca país, la marca de estados, gobiernos e instituciones públicas, de sanidad, educación, deporte, seguridad... Su relación con la heráldica es de «parentesco», tiene un origen y una historia que la justifica, trata así del reconocimiento, la pertinencia y la oficialidad. Conserva mayor rigor iconográfico, se basa, con una mayor fidelidad y respeto, en el código visual heráldico. Pretende una imagen estable y consagrada, por lo que formal y estéticamente resulta más conservadora. Podemos 
decir que la capacidad de su registro visual y estilístico se desenvuelve dentro de lo asumido por la sociedad. Su margen de maniobra para renovarse está sujeto a la tradición estética de su contemporaneidad.
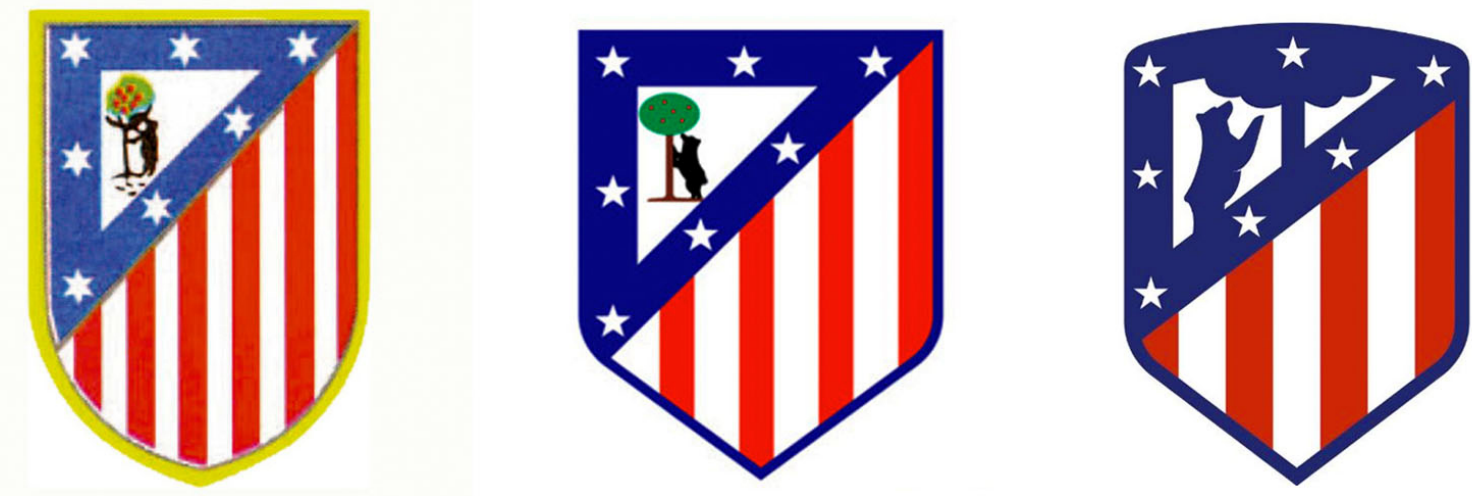

Fig.6. Evolución imagen gráfica del Atlético de Madrid.

Escudo de 1917, diseño de identidad de 2008 y rediseño por Vasava en 2016.

La imagen de marca comercial aborda el grueso de identidades visuales de marca de empresas y entidades privadas, marcas automovilísticas, deportivas, textiles, marcas de electrodomésticos y tecnología, packaging y etiquetado... La marca comercial, que concurre al mercado de la competencia, resulta más atenta a su identidad visual, la perfecciona, optimiza y aproxima a la sociedad constantemente. La transfiguración de las leyes heráldicas y la libertad en sus representaciones mejora su función distintiva, depurando las cualidades ya referidas y optimizando su eficacia. Se trata de una usurpación formal de códigos y recursos, una apariencia de lenguaje heráldico altamente orientado a su eficacia visual y capacidad comunicativa y emotiva. Debe resultar además versátil y soportar distintas condiciones y aplicaciones. En este ejercicio de condicionantes e intencionalidad la imagen se depura, estiliza, abrevia y esquematiza. Aquí la relación con la heráldica es de apropiación, mediante el recurso de la apariencia se hace con sus valores asociados.

De esta manera convendremos que la heráldica pervive en la mecánica del ideario social gracias a su explotación práctica. El equivalente contemporáneo de sus funciones, es tarea del diseño. El diseño de identidad es la disciplina que hoy se ocupa de la identificación, de la comunicación y de la promoción de valores y conciencias colectivas. La heráldica, en este contexto, es una herramienta, un recurso que se define teóricamente como una «estrategia de identidad visual»6.

Dentro del diseño de identidad visual Norberto Chaves categoriza diversas estrategias visuales: narrativas, icónicas, heráldicas, abstractas, nominales ilustradas o puramente nominales. La icónica y la heráldica resultan dos de las estrategias de mayor rendimiento y por tanto muy extendidas como veíamos en diversos ámbitos, muy recurrentes para ciertas entidades, por su naturaleza histórica, su origen, o por su pretensión, intencionalidad u objetivo. La estrategia icónica se basa en representaciones figurativas o simbólicas, descriptivas o evocadoras de elementos visuales existentes, sobre los que hay un acuerdo y reconocimiento 
colectivo y una identificación emocional compartida. La estrategia heráldica recurre puramente al repertorio iconográfico de la emblemática, las banderas y los escudos, esta iconografía siendo histórica y geopolítica, produce los mismos efectos que la definida como estrategia icónica y de la que sin duda forma parte. Ambas estrategias están respondiendo a una de las necesarias características que debe reunir un diseño de identidad visual, la «capacidad emblemática», la capacidad de la imagen de reconocerse como propia, y que tiene la voluntad y la misión de satisfacer una identificación social, local, nacional, cultural... de forma colectiva y no cuestionable.

Javier González Solas ${ }^{7}$ nos aporta otras definiciones para las estrategias de identidad visual en el ámbito de la institución pública. Define las instituciones públicas como sujetos de identidad con una vocación de permanencia y una orientación estable, «lo que implicará la selección de atributos de fácil aprendizaje, de referencia constante, con un gran contenido simbólico y tradicional». La identidad visual de estas entidades es unitaria o monolítica ${ }^{8}$ "adecuada a los tipos de representación permanentes y unívocos, alejados de lo coyuntural [...]. La configuración de la identidad trasciende las épocas y los individuos». Estas identidades acostumbran por ello a expresarse con una estrategia de visualización cerrada, una «imagen programada con el mínimo de variación posible», de forma que se potencien esos aspectos de estabilidad y raigambre.

La forma de expresión heráldica, conserva sus atribuciones como distintivo simbólico del poder, evocando además la cualidad conectiva de la pertenencia a una colectividad ${ }^{9}$. Es uno de los recursos del repertorio simbólico aceptado y consensuado que adoptan las definiciones culturales.

\section{Durable y vigente}

El primer conflicto en la aplicación de una imagen de identidad heráldica en instituciones públicas está en la naturaleza del objeto a representar y su necesidad de representarse con eficacia. Necesitan satisfacerse dos líneas de funciones que aparentan conflicto de oposición. Tener rigor, ser normativo, tradicional, prestigioso, estable y duradero, trasmitir solidez, seguridad y oficialidad, contra mostrarse y mantenerse actual, activo, dinámico, innovador...

Es fácil, en el ejercicio de imagen de permanencia del sujeto institucional, que la explotación de la identificación desgaste la capacidad de otras funciones más emocionales, como los sentimientos de pertenencia e identidad colectiva. La función identificativa, como hecho comunicativo, se limita a dar conocimiento de sí, hace saber. Pero las funciones más sensibles y emocionales serán las que otorguen a la identificación otras capacidades orientadas a una imagen percibida intencional que como veíamos se relaciona activamente con sus receptores, y es promotora de conciencias y conductas. Es la capacidad de hacer hacer ${ }^{10}$.

7 GONZÁLEZ SOLAS, J. Identidad Visual Corporativa. La imagen de nuestro tiempo, Síntesis, Madrid 2010.

8 Aquí cabe relacionar la imagen totémica de González con la función totémica de la simbología de Mauricio Vitta en tanto en que tratamos la evolución de un recurso primigenio de información e identificación colectiva.

9 VITTA, M. El sistema de las imágenes. Estética de las representaciones cotidianas, Paidós, Barcelona 2003.

10 LEDESMA, M. El diseño gráfico una voz pública, Argonauta, Buenos Aires 2003. [Maria Ledesma plantea tres capacidades fundamentales en la historia del diseño, hacer ver, hacer saber $y$ hacer hacer] 
Entra en juego ahora la pertinencia del lenguaje visual, su capacidad para identificar el tono coetáneo y eficiente al receptor de la comunicación, debe ser un tono dialogante y discriminable en un contexto de lenguaje estético siempre contemporáneo. Debe hablar el lenguaje de su receptor, siendo muy deseable que a través de este realice aportaciones al ideario de la colectividad.

Sobre el conflicto entre la imagen de prestigio, estable y duradera, y la necesidad de constante vigencia de esta estrategia escribía ${ }^{11}$ "por ser largo-placista, corre a veces el riesgo de quedar descuidada, desatendida normalmente por el carácter rentista de su obviedad. Uno de los peligros de esta estrategia es la obsolescencia. [...] el hecho de que exista un acuerdo en los motivos y los códigos de representación, en sus estructuras y jerarquías, como le sucede al lenguaje heráldico, no quiere decir que las figuras allí representadas sean intocables, ni mucho menos que aquellos códigos de representación sean válidos transcurra el tiempo y el contexto que transcurra. Al contrario, la pervivencia de esos códigos se basará en su preciso ajuste a la necesidad de prevalencia atemporal».

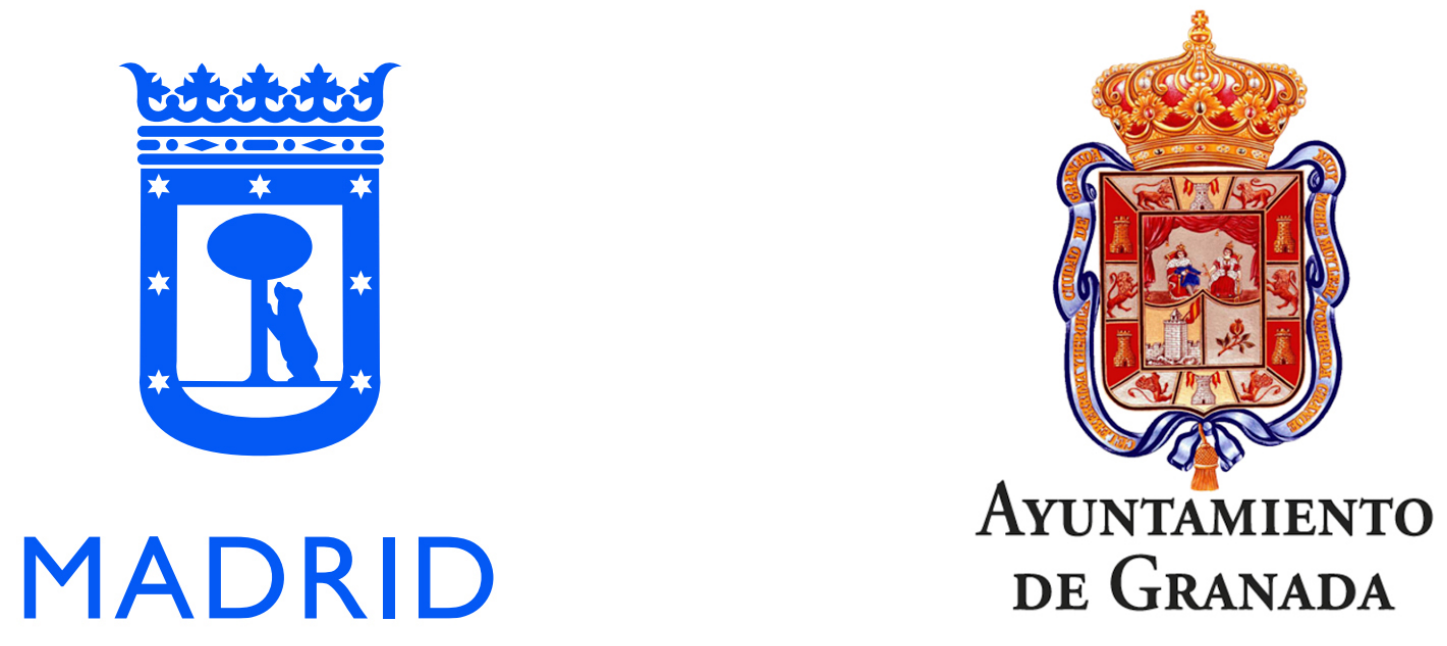

Fig.7. Identidad visual corporativa del Ayuntamiento de Madrid 2016. Actual identidad del Ayuntamiento de Granada.

Estamos concluyendo que desarrollo de identidades visuales basadas en la estrategia heráldica debe contentar una identificación pertinente pero actual. Debe exigírsele al diseño aquella metodología proyectual que investiga analiza y propone fundadamente. Pero debe exigirse al tiempo, una precisa definición del encargo, con suerte consensuarse o conceptualizarse en un proceso que implique al emisor y a sus receptores, se trata de construir una narración y un valor simbólico de forma lo más aditiva posible en su fondo, y lo más concisa y precisa en su forma. Este es el trabajo del diseño, una tarea maestra de discriminar y yuxtaponer. 


\section{El diseño de identidad en la institución pública}
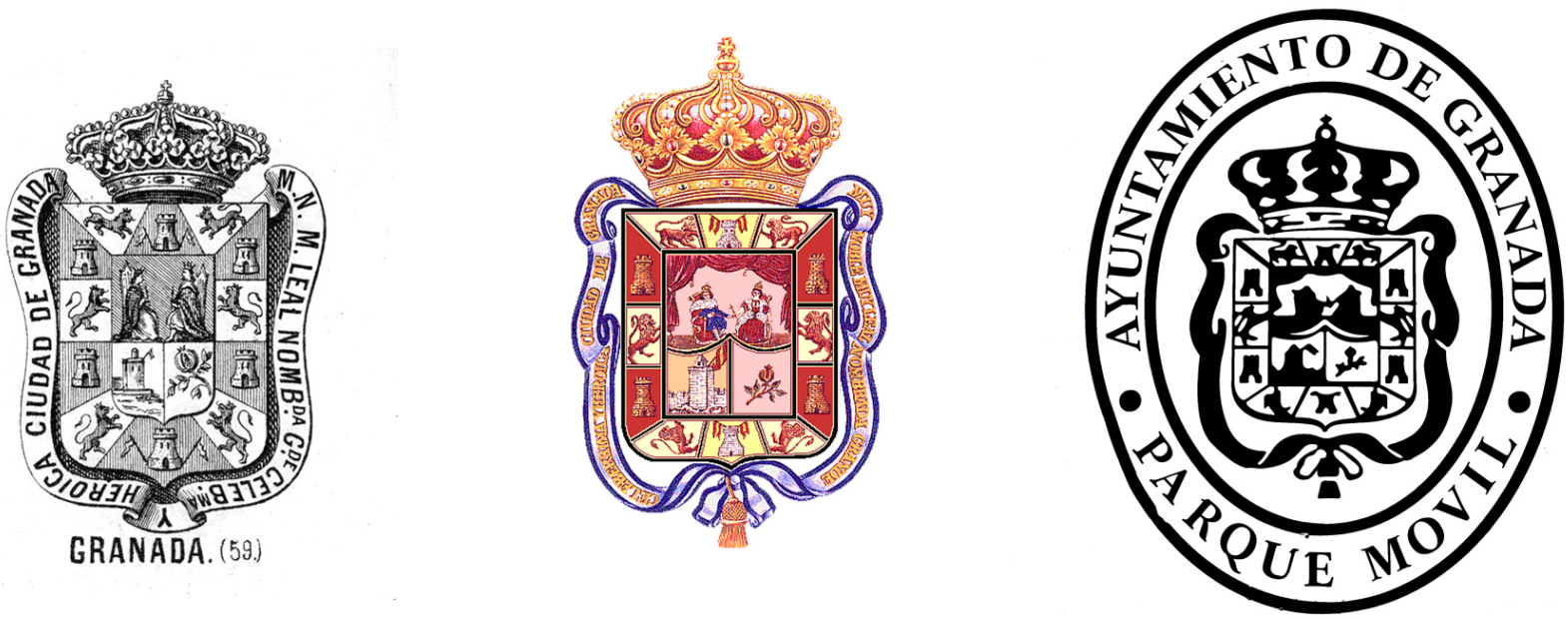

Fig.8. Escudo de Granada 1867. Escudo oficial del Ayuntamiento de Granada y símbolo componente de su identidad visual.

En cierta medida es el consumo del diseño el que posiciona la calidad de este. Si las instituciones adquieren imagen a través de un diseño de calidad favorecen que el conjunto de la sociedad y el mercado tienda a emular la consideración de su rentabilidad. Es un aval de garantía y prestigio. La marca comercial consolidada ya se expresa eficazmente gracias a la configuración de sus identidades, con mayor visibilidad y presencia que la imagen de marca institucional, que requiere ahora una atención importante y una programación estratégica.

En el ámbito profesional los ejemplos de grandes figuras del diseño y su trabajo para diversas instituciones de primer orden ponen de manifiesto que el diseño de identidad basado en la estrategia heráldica está integrado en el tejido productivo, económico y comunicacional. Se reconoce así la importancia que para la imagen percibida de la institución tiene este tipo de diseño. No obstante el déficit que presentan la mayoría de los organismos oficiales y entidades públicas de segundo rango puede valorarse generalizado ${ }^{12}$.

De parte del diseño podemos advertir ciertos efectos como cuestionables. Es habitual encontrar reacciones críticas a estas intervenciones. Las entidades heráldicas acostumbran a denunciar la despreocupación y el desconocimiento del lenguaje heráldico y sus códigos. Convendremos con ellas que desatender rigores iconográficos, símbólicos o narrativos puede desfigurar el contenido y efecto deseado de la comunicación. Pero de nuevo la cuestión es reversible. De la misma manera una norma disciplinar estática, como una ley del blasón, puede resultar discriminable para la necesidad de esta otra disciplina, el diseño, que fundamentalmente se apropia de aquellos recursos y los optimiza en un sin fin de sujetos de identidad de diversa índole y dispar necesidad.

De parte de la institución el mayor problema es la escasa consideración del diseño como agente imprescindible

12 Organismos públicos como diputaciones, municipalidad, universidades, entidades sociales... 
para proyectar una imagen útil y pertinente. En consecuencia es habitual una mala gestión en la integración y mantenimiento de la comunicación institucional. Es un espacio complejo, la densidad y el volumen de los organigramas de estas instituciones dificultan el reconocimiento de conceptos de prioridad más transversales como la comunicación eficiente de su propia identidad. En este sentido la institución puede mostrar tres principios de actuación:

a) Concurrir al mercado del sector competente en materias de diseño y comunicación, externalizando la solución a su necesidad.

b ) Integrar equipos de diseño en el propio organismo.

c) Ejecutar soluciones precipitadas, improvisadas o cortoplacistas.

\section{Conclusiones y recomendaciones para el diseño de identidades visuales en el ámbito de la institu- ción pública.}

Dentro de un estudio más amplio que intenta generar una metodología proyectual específica para proyectos de identidad visual corporativa en entidades institucionales universitarias, este artículo favorece un diagnóstico, un espacio de observación que permite extraer estas conclusiones sobre los modos en que las instituciones pueden abordar la imagen que proyectan de si y de sus actuaciones.

Concurrir al sector profesional del diseño será una garantía de eficacia capaz de resolver necesidades concretas, aunque generalmente aisladas. Retornará eso si tanto en la imagen percibida de la institución como en la dinámica productiva, fomentando un reconociendo del diseño y del trabajo de agencias y estudios.

Integrar equipos de diseño en el propio organismo institucional tiene un beneficio para la gestión de un concepto de imagen global. Con conocimiento interno del conjunto de sus necesidades es posible diseñar programas y estrategias con capacidad de facultar al conjunto de su organigrama de una comunicación integrada y coordinada.

Optar por soluciones precipitadas e improvisadas es evadirse de la importancia de la propia identidad visual. No atender a estas consideraciones ha generado una singular intrusión del diseño difuso en los procesos de adquisición y gestión de los servicios de diseño. Ejemplos frecuentes en el panorama de la gráfica institucional son los concursos, que desde el diseño estamos acostumbrados a denunciar, de bases con escaso conocimiento disciplinar, sin tribunal especializado y con premios inferiores a los precios de mercado, que imposibilitan la participación de proyectos profesionales de calidad y finalmente deprecian el valor del diseño. Tanto está extendido otro fenómeno de singular naturalidad como son las soluciones internas no cualificadas, en las que voluntariosos creativos de especialidades ajenas «hacen uso de su capacidad natural para el diseño ${ }^{13}$ y ocasionan un sin fin de imágenes para el divertimento y descalabro de los especializados en la materia. La democratización tecnológica suma a todo ello la accesibilidad a un repertorio infinito de recursos,

13 MANZINI, E. Cuando todos diseñan. Una introducción al diseño para la innovación social, Experimenta, Madrid, 2015. 
que permiten una aparente solvencia estética, y amenazan una vacua homogeneidad estilística de tendencia. Estos efectos, de riesgo procedimental, deben ser valorados para evitar un efecto que difumine, confunda y malogre la imagen institucional.

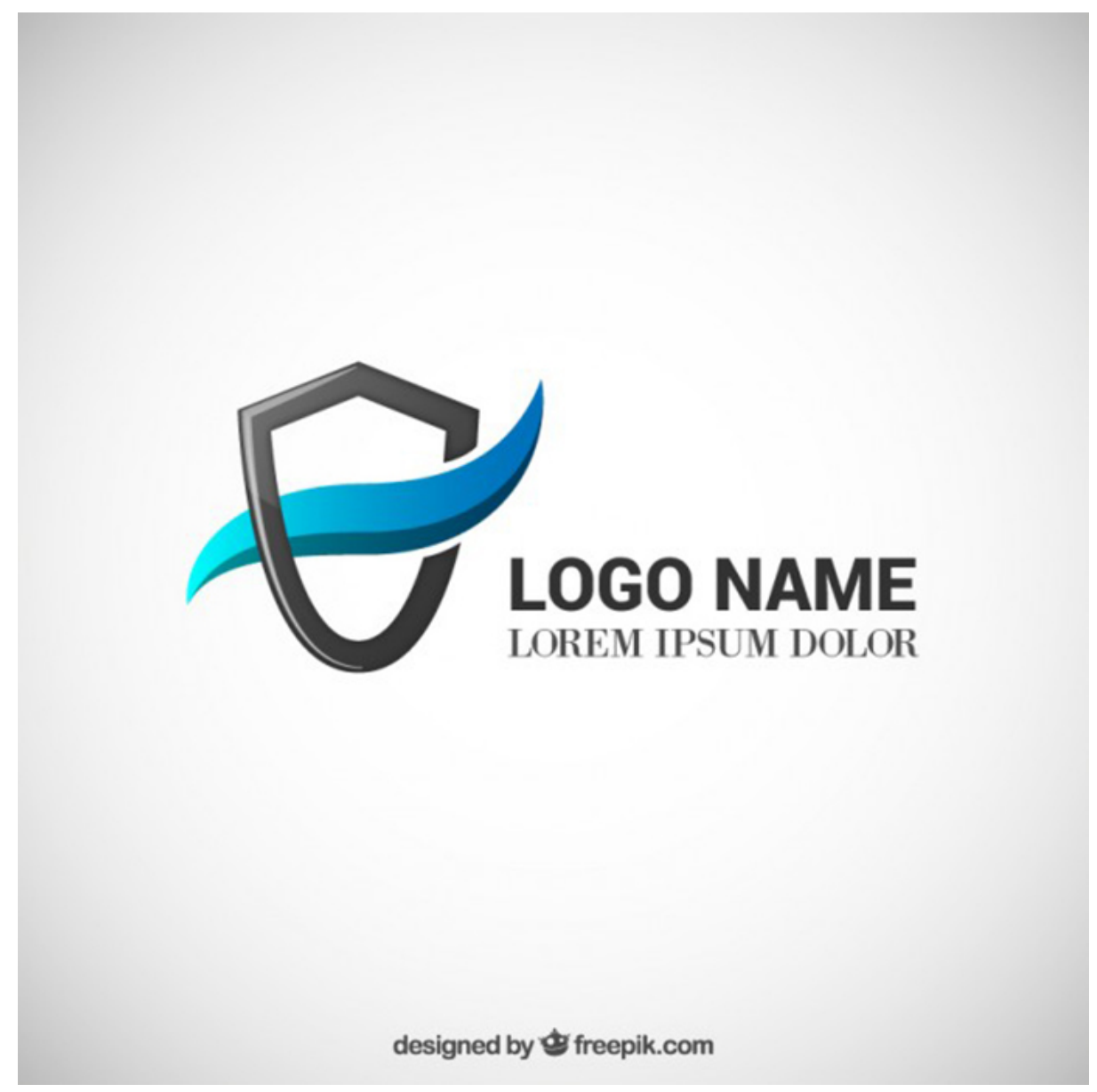

Fig.9. Mockup o plantilla de diseño predefinido. Freepik. 


\section{Bibliografía}

CHAVES, N. El diseño invisible, Paidós, Barcelona 2005.

CHAVES, N. La imagen corporativa. Teoría y metodología de la identificación institucional, Gustavo Gili, Barcelona 1990.

CHAVES, N. y BELLUCCIA, R. La imagen corporativa: gestión y diseño de símbolos y logotipos, Paidós, Barcelona 2003.

CHAVES, N, VVAA. Diseño y comunicación, teorías y enfoques críticos, Paidós, Buenos Aries 2003.

COSTA, J. Imagen corporativa en el siglo XXI, La Crujía Ediciones, Buenos Aires 2003.

COSTA, J. La imagen de marca. Un fenómeno social, Paidós, Barcelona 2009.

COSTA, J. Diseño comunicación y cultura, Fundesco, Madrid 1994.

COSTA, J. Imagen global. Evolución del Diseño de Identidad, CEAC Enciclopedia del Diseño, Barcelona 1989.

DE CADENAS Y VICENT, V. Diccionario heráldico: términos, piezas y figuras usadas en la ciencia del blasón, Hidalguía, Madrid 2002.

DONDIS, A. D. La sintaxis de la imagen, introducción al alfabeto visual, Gustavo Gili, México 1995.

GONZÁLEZ SOLAS, J. Identidad Visual Corporativa. La imagen de nuestro tiempo, Síntesis, Madrid 2010.

LEDESMA, M. El diseño gráfico una voz pública, Argonauta, Buenos Aires 2003.

MANZINI, E. Cuando todos diseñan. Una introducción al diseño para la innovación social, Experimenta, Madrid 2015.

MEDIAVILLA, G. La Comunicación corporativa en el deporte: cómo organizar y gestionar la imagen de una empresa, institución o evento deportivo, Gymnos, Madrid 2002.

OLINS, W. La imagen corporativa internacional, Gustavo Gili, Barcelona 1995

PARDO DE GUEVARA, E. Manual de heráldica española, Aldaba, Madrid 1987.

RAMOS FERNÁNDEZ, F. La comunicación corporativa e institucional. De la imagen al protocolo, Universitas, Madrid 2002.

SANZ, J. «Siempre es ahora» La mirada del águila. Pasado y futuro de la Universidad de Granada a través de sus símbolos, Universidad de Granada, Granada 2017.

SATUÉ, E. El diseño gráfico. Desde los orígenes hasta nuestros días, Alianza, Madrid 2006.

SATUÉ, E. El diseño gráfico en España. Historia de una forma comunicativa nueva, Alianza, Madrid 1997.

SOTELO, C. Introducción a la comunicación institucional, Ariel, Barcelona 2001.

VITTA, M. El sistema de las imágenes. Estética de las representaciones cotidianas, Paidós, Barcelona 2003. 
VILLAFAÑE, J. La gestión profesional de la imagen corporativa, Pirámide, Madrid 2004.

Webgrafía

CHAVES, N. La marca país [Conferencia del Seminario de Capacitación sobre el desarrollo de "La marca país»], Jefatura de Gabinete de la Provincia de Buenos Aires (28.08.2012).

\section{Índice de imágenes}

Fig. 1. Batalla de Aljubarrota, 1385, British Library, Royal 14 E IV f. 204 recto.

Fig. 2. Formas de escudos según procedencia. En Cadenas y Vicent, V. Diccionario heráldico, términos, piezas y figuras usadas en la ciencia del Blasón.

Fig. 3. Grabados calcográficos de heráldica, Ciencia heroyca, reducida a las leyes heráldicas del Blasón, Ed. Joaquín Ibarra, 1754-1785. BNE.

Fig. 4. Representación del siglo XVI, Museo arqueológico provincial de Valencia y representación heráldica contemporánea del escudo de la Comunidad Valenciana. Wikipedia.

Fig. 5. Identidad visual de la Generalitat Valenciana diseñada por La Nave en 1984 y su rediseño de nuevo por Nacho Lavernia y Daniel Nebot en 2018.

Fig. 6. Evolución imagen gráfica del Atlético de Madrid. Escudo de 1917, diseño de identidad de 2008 y rediseño por Vasava en 2016.

Fig. 7. Identidad visual corporativa del Ayuntamiento de Madrid 2016. Actual identidad del Ayuntamiento de Granada.

Fig. 8. Escudo de Granada 1867. Escudo oficial del Ayuntamiento de Granada y símbolo componente de su identidad visual. Reproducción de una aplicación en vinilo de corte sobre vehículo oficial 2018. En esta última imagen se ponen de manifiesto varias problemáticas. Desde cuestiones técnicas y gráficas como la visibilidad, legibilidad, reproducibilidad, a la consecuente necesidad del programa de diseño de identidad, y hasta fenomenologías como la autoedición no especializada.

Fig. 9. Mockup o plantilla de diseño predefinido. Freepik. 